\title{
The state of the pastoral economy of the Solon Evenki: Focusing on the logic of their communities
}

\author{
Nasunmenghe \\ Graduate School of Agricultural Science \\ Tohoku University, Sendai, Japan; \\ Kohei Yagi \\ Policy Research Institute of Ministry of Agriculture \\ Forestry and Fisheries, Tokyo, Japan;
}

\begin{abstract}
Although organizations such as hamlets and clans have often been regarded as an impediment to modern development, in fact they provide organizational principles that are indispensable in supporting modern economic development. In this paper, we describe livestock farming in the Solon Evenki in the Evenki Autonomous Banner in the Hulunbuir area of China's Inner Mongolia Autonomous Region in detail and then explain how the system changed due to the prohibition of nomadism and the roles the communities played.

The results are as follows. First, although their main daily business is livestock farming, there are several sources of revenue, and it is characterized by diverse and rich economic activities mainly on small-scale pastoralism. However, with the development of non-renewable resources such as coal, this economic structure is being scaled up and simplified, so that temporary economic gain might result in the risk of long-term economic weakness. Second, looking at the actual pasture use, we see that there is no clear line between private pasture and common land. As the partitioning off of land incurred significant transaction costs, local social relations functioned to regulate it in an ad-hoc manner.
\end{abstract}

Keywords: Evenki; pastoral economy; community; rural society

\section{INTRODUCTION}

Although organizations such as hamlets and clans have often been regarded as impediments to modern development, they actually provide organizational principles that are indispensable in supporting modern economic development[1]. Hayami[1] states that 'Communities assume the role of dividing labor into appropriate cooperative relationships through consensual cooperation.' In this paper, we examine the kinds of functions such communities serve in regard to pastoral and other livelihoods among the Solon Evenki people in the Evenki Autonomous Banner of Hulunbuir area of China's Inner Mongolia Autonomous Region.

The Solon Evenki people were once nomadic, until the period of the people's communes (rénmín gōngshè), when nomadism was prohibited and they were forced to live settled lives. In addition, each household began to lease land. The rural land tenure system was introduced after the people's communes were abolished in 1978, and it contracted the management of agricultural land to households under state ownership. In regard to the pastoralists of Inner Mongolia, this is called the contracting of pastures (căo chăng in Chinese). This systemic change was intended to incentivize profit-seeking economic activity by conferring property rights to the people. However, some matters could not be dealt with solely by economic rationalism, which meant that community-based measures were also needed. In this paper, we 
describe Evenki livestock farming in detail, and then explain how the system changed and the roles communities played in these changes.

This paper focuses on the Evenki Banner, who are one of the indigenous peoples of the Siberian Plateau and call themselves 'Evenki'. Evenki means 'people who live deep in the mountains'. Today, the Evenki live in Russia, Mongolia, and China. The Evenki Banner, which lies within Chinese territory, is classified into three peoples: the Tungus Evenki (also known as the Khamnigan Evenki), the Solon Evenki, and the Yakut Evenki (Aoluguya Ewenke)[2]. The Evenki whom we discuss in this paper are the Solon Evenki, who are a Tungusic people. They fled Russian domination in the early 17th century and migrated to the area along the Amur River, which is now in Heilongjiang Province (China), quickly pledging allegiance to the Qing Dynasty. Based on its own Eight Banner system, the Qing Dynasty reorganized the Solon Evenki in the Manchu fashion, which it called the 'Eight Banners of Solon'. This compelled the Solon Evenki to change their livelihoods from hunting to nomadic herding and restricted their grazing areas[3]. By 1905 the current population in the area corresponding to the present-day Evenki Autonomous Banner was 3,028 Evenki, 716 Daurs, and 651 people belonging to a Mongol tribe. The Solon Evenki live among the Mongol and the Daur peoples, and, until the 1980s, they lived nomadically on the steppes of Inner Mongolia. However, after that, their pastures were leased out under the Chinese government's rural land tenure system, and they have been living as settled pastoralists ever since.

Recent research conducted in Chinese and Mongolian includes reports on the current state, the origins, and the traditional culture of Evenki society, such as by the National Ethnic Affairs Commission of China[4] and $\mathrm{Du}$ [5] in Chinese and Sirenbat et al.[6] in Mongolian. Research reports by Kamimakise[7], Qiu[8], Peter[9], Yanagisawa[10], Xi[11], and others have also mentioned the Solon Ewenki or Aoluguya Ewenke. Nasunmenghe and Yonekura[12] focused on the Juu, a group that is the smallest unit of kinship, and wrote in detail about the roles of pastoral and livestock management, land management, and property distribution. However, while these studies do discuss the function of the Juu in detail, they do not present an overall view of livestock farming. In this paper, we will present basic material to understand the state of pastoralism among the Evenki and explain the way in which their community principles functioned.

We conducted field research in August and September 2012 in the Evenki Autonomous Banner of Hulubuir, mostly in a gacha (village) inhabited by Evenki pastoralists. The Evenki Autonomous Banner is located on the west side of Daxing'anling Prefecture in northeastern Inner Mongolia, at the southeastern edge of Hulunbuir. For this paper, we chose a gacha in an area where we could observe various changes intensively. We conducted interviews with pastoralists in which we surveyed them about their daily activities, lifestyle, and social relations. For the purposes of anonymity, we will denote our research site as Gacha A of Sumu B. Gacha A is one of the three gacha that belong to Sumu B. At this point, sumu corresponds to the township.

\section{HISTORICAL BACKGROUND}

The total area of the Evenki Autonomous Banner is $19,111 \mathrm{~km}^{2}$, and the Evenki and other ethnic groups have moved where the grass is suitable and let their animals graze for generations. According to the qi zhi[14], Hong Taiji and later Qing emperors launched military invasions into the areas where the Evenki, Daur, and Oroqen lived on three occasions, subjugating them and relocating them to an area south of present-day Qiqihar. The Solon Evenki were called 'hunter hamlets' in the Qing period, and records show that their main livelihood was hunting. Subsequently, some of them moved to the plains in the north, whilst 
the Qing emperors subjugated others. Based on its own Eight Banner system, the Qing Dynasty reorganized the Solon Evenki in the Manchu fashion, which it called the 'Eight Banners of Solon'. This reorganization influenced the Solon Evenki's livelihoods to change from hunting to nomadic herding and restricted their grazing areas[3].

During the people's commune period (organisation at the sumu level), the Evenki bred livestock and let them graze within the sumu as a common property of the gacha. Since the livestock were common property, the whole gacha worked, and when they fulfilled their work quota, it was recorded as 'points' every day and aggregated on an annual basis. The gacha was referred to as a production brigade at the time, and each production brigade distributed the production and earnings. If the revenue of the whole production brigade went down, its score was accordingly reduced by one point, and the annual income of each farmer decreased since the workers' incomes were calculated based on the points recorded. The total annual score was allocated by the gacha-da, who is the head of a gacha, as revenue ${ }^{4}$. At the time, Gacha A had a satisfactory pasture yield and was able to reach each year's quota, so the annual income per farmer was 20-30 yuan in the money of that time, which was sometimes double the annual income of other gacha in the commune.

Towards the end of the people's commune period, there were five otur for the livestock shared by the production brigade. In this area, otur refers to campgrounds to which pastoralists temporarily leave their settlements and head with their herds of sheep and cattle in tow, along with basic supplies[13]. Each otur of the shared livestock was overseen by five Juu, who switched more or less yearly. The otur members typically consisted of a farmer couple and one or two other Juu workers. If there were any 'intellectual youths' (during the 1980s, there was a state policy of dispatching outstanding youths from Shanghai, Tianjin, and other big cities to remote regions) or 'rural intellectual youths' (there was also a regional policy of supporting local pastoral economies by dispatching youths from the banner to the sumu and gacha), they would also be added as otur workers. In most cases, 3-4 people used an urge-Juu together, with each otur consisting of one or two ugge-Juu, moving the otur around and letting cattle and sheep graze in areas with good pastures.

The people's communes of the Evenki banner were dismantled between 1982 and 1983, and the common property livestock were distributed for private ownership. With the introduction of the land leasehold system in 1985, the production responsibility system was also implemented. With the private distribution and fixation of land use rights, the kind of largescale grazing that existed during the people's commune period disappeared. At the site of study in Gacha A, private individuals took over the responsibility for the communal cattle after the dismantling of the people's communes. There were no cattle left after the distribution, but there were about 600 sheep that were sold off. The proceeds from the taking over and selling the livestock became the shared property of the gacha, which was the continuation of the production brigade.

Around this time, the gacha did not function as an administrative unit, but was no more than a place of long-term residency for specific purposes, such as children's schooling, for households engaging in settled pastoralism on a small scale. The members of the production brigade bred their privately owned livestock and had them graze around their own urge-Juu. Most livestock farmers in Gacha A had also made a living by breeding private livestock on the Juu level, aside from the livestock jointly owned by the commune, during the people's commune period. 


\section{The Current State of Pastoralism in the Evenki Autonomous Banner Outlook of Pastoralism}

The economy of the autonomous banner has grown since the year 2000. The autonomous banner's GDP was $10,054,630,000$ yuan (RMB) in 2017, showing a growth rate of $5.0 \%$. The GDP per capita was 72,316 yuan. As of 2017, the industrial structure was $7.2 \%$ primary industry, $64.3 \%$ secondary industry, and $28.5 \%$ tertiary industry. The table below shows that the number of livestock in the agricultural and pastoral industry increased from the previous year. According to 2017 data, milk production was 170,000 tonnes, an increase of 10.4\% over the previous year. Meat production also increased by $0.3 \%$ to 19,154 tonnes.

Table 1. Number of Livestock in the Autonomous Banner. (Unit: 1 animal)

\begin{tabular}{|l|l|l|}
\hline & End of 2016 & End of 2017 \\
\hline Cattle & 98,376 & 104,066 \\
\hline Horses & 40,128 & 39,403 \\
\hline Camels & 1,004 & 700 \\
\hline Sheep & 465,897 & 494,377 \\
\hline Pigs & 11,000 & 12,400 \\
\hline Number of livestock & 658,475 & 685,205 \\
\hline
\end{tabular}

\section{Dairy}

Under the production responsibility system that was introduced after the dismantling of the people's communes, households of pastoralists breed cattle, sheep, and horses on the leasehold land allocated to them. Across the Hulunbuir area, the average household lives mainly off sheep sales and manages more than 1,000 grazing animals, but there is currently an increase in cattle in Gacha A, which is turning dairy sales into a principal source for cash revenue and can well be characterised as a dairy-farming economy. Of the 138 households that participated in the survey, 109 are breeding cattle and 87 are selling milk. The number of cattle is also increasing. There is a total of 1,800 cattle in the whole gacha, with about 13 on average per household. Aside from dairy, meat cows are also raised, but the proportion is small. There are no meat cows raised as such from the beginning, but some are sold as meat cows after they stop producing milk. In this section, I give a detailed account of the dairy industry that is becoming a principal source of revenue for the Evenki today.

According to the Editorial Committee of the Gazette of the Evenki Autonomous Banner [14], looking at the milk collection, there were five dairy-product companies in the Evenki Autonomous Banner at the time. 68 fixed dairy farms were registered, of which 31 were temporarily closed and 27 in operation in 2009. There were also 10 outside the country (Mongolia). From looking at just the five dairy-product companies in the banner, the milk collection income decreased annually. Depending on the quality, $1 \mathrm{~kg}$ was worth 1.2-1.7 yuan when collected by pastoralists directly. However, milk was $0.5-0.7$ yuan, meaning less than 1.0 yuan, in the adjacent areas.

As a consequence of the 2008 scandal of dugs mixed into powdered milk (the Sanlu scandal), demand dropped sharply, and many dairy farms closed down. With this, the banner government's relevant departments launched the measures described below in a bid to resolve this situation, which has led to the recovery in dairy production today. As of 2018, there are three dairy-product companies in the autonomous banner, but there are no milk sales as most of the production is of powdered milk and ice cream. These three companies collect milk from livestock farmers in the autonomous banner and do so primarily in the banner's south, 
collecting almost nothing in Sumu B. San yuan Dairy, which is the biggest of the three and provides fresh cream, ice cream, and powdered milk centring on Hailar, collects milk in Sumu $B$, which also includes the site of study of Gacha A. There are no milk producers in the autonomous banner. At present, two companies in Hohhot, Meng niu and Yi li, provide the milk that can be found in Hailar and the banner.

The measures that made the dairy production's recovery possible today had to do with repairing and re-establishing relationships between companies, the dairy industry, and the pastoral households with the livestock. Both the buying and the selling of the milk specified sales prices depending on the quality and fixed purchase prices. One has to look for high quality and conduct purchases and sales based on equal and mutual interests. These measures softened the tensions between the companies and the pastoralists, and better motivated productivity among the stock farmers.

\section{Use of Leasehold Land in Gacha A}

As regards the leasehold land used for the grazing at the site of study, land distribution and leasing started in 1985, with a lease period of 15 years. This period was extended to 30 years in 1997. Households leased the land, and usage certificates were given to the household heads in 1998. These leasehold lands cannot be used for any purpose other than grazing and also cannot be sold. 82 out of 138 households in Gacha A lease land and nearly all the households' pieces of leasehold land are categorised as either 'hay-mowing' or 'pastures' depending on their purpose of use, which is indicated on the 'usage certificates'.

Hay-mowing' are pieces of land leased to farmer household heads to be used for hay-mowing and grazing, whilst 'pastures' are for livestock to graze on. About 60,000 mu of land was subject to leasing in Gacha A, with some becoming the residential areas and mansions of Urileng and the rest becoming pastures. Pastures not subject to leasing are generally referred to as 'common land'. Since the actual location of the leased 'pastures' also is undetermined, they are treated the same as the 'common land'. The livestock farmers simply designate locations according to the instructions of the gacha-da, so undesignated land is considered common land. According to field survey, 128,401 $\mathrm{mu}$ of the leasehold land in Gacha A is 'haymowing', whilst 23,145 $\mathrm{mu}$ are registered as 'pastures' in the 'usage certificates'. All of the areas can be grazed, but the livestock farmers told me that the common land or pastures that actually exist are much less than indicated. Moreover, no one knows where the leased pastures are located. This confusion arises because, although the grazing is done on the gacha's common land, that land has simply been allocated to each household as a number with no actual designation of its location. As such, what is common land has always been highly vague, and the confusion has only deepened as a portion of it has been further distributed to some livestock farmers as 'hay-mowing'. In fact, since all land except for that given to private individuals as land for hay-mowing could potentially be common land, there is on-going conflict over it. Thus, while common land has been allocated, there are transaction costs involved in partitioning it off, which effectively means that its management is governed the logic of social relations.

In addition, common land encompasses more than this in practice. These pastures are divided into two kinds of otur, namely pastoralist GMDG and pastoralist SR. Aside from these otur, most of them are otur located on pastures that have been converted from part of their own hay-mowing land. In general, 300-500 sheep graze per otur. Table 2 below shows one example of a pastoral GMDG otur set up on common land. As indicated by this example, there are generally 300-500 sheep per otur. The grazing sheep are the sum of sheep owned by the five 
households that make up a Juи. These sheep owners are siblings or parents and children, and, whilst they make up a Juu, they are also independent households, and normally each make their own living. Taking into consideration the sizes of the livestock flocks, those who own considerably more animals will take care of the smaller numbers owned by other family members, including those sheep in their own flock and managing them there. Out of the 500 sheep in this otur, about 350 belong to the GD household that manages the otur, whilst the other 150 belong to the other four households. Otur were thus established on common lands by Juu consisting of multiple households, though while the number of livestock owned is counted per household, in practice they are managed by a single large household due to economies of scale. Therefore, social relations at the Juu level manage the common property.

Table 2. Otur Example

\begin{tabular}{|l|l|}
\hline Area & $3 \mathrm{~km}^{2}$ (near Urileng) \\
\hline Number of Grazing Livestock & 500 sheep \\
\hline $\begin{array}{l}\text { Number of Permanent } \\
\text { Residents }\end{array}$ & $\begin{array}{l}4 \text { (household head and his wife, as well as a married couple hired as } \\
\text { workers) }\end{array}$ \\
\hline Worker Wage & 4,000 yuan (married couple)/ month \\
\hline
\end{tabular}

Source: Complied based on household-survey data.

\section{Livestock}

Settled pastoralism is the key industry, and most of the livestock are cattle, horses, and sheep. There are also some goats, but their proportions are small at just 30 or so goats mixed into a flock of 300 other animals. The livestock are either sold or consumed by the household. The household consumption can further be divided into food (meat, milk, dairy products) and skins used for protection against the cold. According to the Evenki statistics for 2007, the total number of livestock in Gacha A was 6,458, of which were 1,593 cattle, 4,484 sheep, and 381 horses. At the time of the 2015 survey, there were 1,866 cattle, 7,346 sheep, and 710 horses. Below, I estimate the number of livestock today based on interviews with households in Gacha A and government data.

The livestock veterinarian department of the sumu where Gacha A is located conducts vaccinations each year in September through October to prevent parasites and disease amongst the livestock. The number of cattle mainly comes from responses to my interview survey, but when the response was 0 , I used the vaccination data. For the number of sheep, I compared the numbers from the vaccinations that I accompanied with the interview data from individual households and used the higher of the two. Since sheep and goat flocks were raised together, it was also difficult to count the goats. The sheep estimates include goats, but goats make up less than $10 \%$ of the flocks. The number of horses comes from the interview data. At present, the livestock farmers of Gacha A primarily breed the three animal types of cattle, horses, and sheep (including goats), with the biggest group being cattle-breeding households at 82. The sheep are the most numerous and the horses the least. Besides the Evenki banner, three more banners are living mainly off pastoralism in the Hulunbuir area, and the sheep numbers there are overwhelmingly higher, frequently exceeding 1,000. By contrast, it is rare for an Evenki banner household to own more than 300 sheep, and it is more common to own only a few dozen. Most of the horses were previously used for riding, but, in recent years, the need has diminished with the spread of motorcycles, and the number of horses has gone down rapidly. Now horses are bred only to be sold. However, looking at the situation at the time of the survey in August 2015, there was an increase in people owning large numbers of horses for the first time, the majority being livestock farmers who were compensated for this. Some 
bought mixed-breed horses for 100,000 yuan in case of unique breeds that were not local. The survey also reveals the annual income of the 138 households in Gacha A.

If we take a look at the revenue structure, there is almost no revenue from skin and meat sales, but the primary revenue comes from milk provisions to dairy factories. In other words, it would undoubtedly appear that milk sales are a stable revenue source for all of Gacha A. Aside from this principal revenue, there is secondary revenue in the form of the direct sales of livestock. Besides the above, there were also two workers working away from home, two private taxi drivers, one in a shop, eight persons in receipt of minimum social security support, 31 persons employed and paid as government officials, and persons who lend pastures. Moreover, in recent years, public pastures and several households' private pastures have been expropriated for coal mining. The payment of large sums as compensation for the lands has made some farmers sell all their livestock, whilst the even distribution of compensation for public pastures has reduced the number of persons working away from home, as their need for external income has decreased.

The livestock prices in 2013-2014 were 1,200 yuan for a sheep, 5,000 yuan for a cow, and 7,000 yuan for a horse. Most cattle and horses are sold to merchants coming from outside the gacha in trucks. Mother sheep are seldom sold, but about half of the lambs are sold at markets every year, whilst a certain number are kept. Lambs are sold for 700 yuan. I should also mention that, according to pastoralist HM (45 years old, woman, interview respondent), she sold 60 lambs in 2014 and 80 in 2015 . The scale of livestock in Gacha A is coupled with the market economy, and the numbers and types of livestock change to some extent depending on how their market worth develops.

However, coal mining development expansion has caused the expropriation of even more of Gacha A's livestock farmers' pastures, so that nearly all households have received some compensation in the two most recent years. This expropriation signifies a shift in the principal source of revenue for farmers from milk sales to compensation for pastures, in effect making milk and livestock secondary revenue sources. Livestock prices on the market have stopped influencing the number of livestock kept, and there are frequent cases of compensated livestock farmers buying more sheep as a form of savings despite the low prices. This use of sheep as a form of savings might lead to a greater tendency to breed sheep and a further considerable increase in the number of sheep. Although the coal mining development has the benefit of temporarily increasing the livestock farmers' income, it goes without saying that it is damaging the small yet diverse economic activities that have become established in the area. After they acquired large sums of money through the distribution of compensation, the livestock farmers could move into the cities and live much more comfortable lives. Despite this, we see an expression of their unique worldview in that they maintain their ways of life even after changing their livestock for compensation. This continuation of traditional ways is likely because their 'Evenki-ness' that has been maintained for centuries is sustained by the image of the pastoral farmer.

\section{Hay-Mowing}

The growth of grass depends mainly on the weather. The winters are long and the temperatures low in Hulunbuir, whilst the summers are short and cool. Springs are windy and dry, and autumns have large drops in air temperature and significant differences in temperature between day and night. There is not enough rainfall, but concentrated amounts do fall in July and August. The pastures grow well when there is enough rainfall, but there is drought otherwise. 
Heavy winter snows kill livestock and autumnal drought withers pastures (pressing issues include grassland desertification and declining biodiversity). In this way, the local pastoralism very much depends on nature.

Local livestock farmers use most of their leasehold land for hay-mowing. They may be leasing anything from 300 ha to 80 ha. In the 1990s, hay harvesting in the autumn was called 'knifehand' and was done by hand. Entering the 2000s, they started using small agricultural mowers pulled by tractors, and in the 2010s, they started using large mowers. In the 1990s, they would hire Han-Chinese workers from neighbouring villages on one-month contracts, setting up these 'otur' at the mowing sites and having them stay there for the duration of the work. The harvest was divided $3 / 7$, and the workers were compensated with one-third that they could take back to their village. Most of these Han-Chinese workers did not have any leasehold land of their own, and so they would often have cattle and sheep in a neighboring village. In the 1990s, people would use 'haduur' (a moon-shaped blade that extends to the ground with the handle erect, used for hay-mowing) to mow the hay manually. In the second half of the 1990s, this was changed to small mowers pulled by agricultural tractors with 22 horsepower. Many Han-Chinese workers had tractors, and the investments in machines and the workforce allowed them to increase their compensation to 5/5. As such, the Evenki also started using tractors, which greatly reduced the work time. Furthermore, when 13 households received compensation for coal-mining land expropriation in 2009, they bought large tractors, large mowers, hay balers, and other machines. A stock farmer called KKY bought a large tractor and mowed hay for compensation. It took one week to finish 300 ha of land. He was compensated either in cash or in hay bales. The introduction of large machines sped up hay-mowing tenfold. After the autumn's hay-mowing, the livestock is allowed to graze at both pastures and hay-mowing grounds, but, in winter, when the grasslands are snow-covered, they are often kept in barns. When the otur move into the barns, the livestock are driven by motorbike, and the mobile homes (trailers often in use today) are moved by a tractor.

\section{Feeding Techniques: Barn Breeding and Grazing}

House districts are common land of the gacha not subject to leasing where households were later allowed to occupy the land to build houses. Whilst called house districts, they can be dozens of ha in size, and one household can have more than 1 ha, where they would build their housing, garage, and barn, separating living and livestock areas. In this way, the residential areas are expanding. 76 households in Gacha A have cattle barns, all made out of brick and concrete. The surface area is usually about $200 \mathrm{~m}^{2}$, and both milking and feeding take place there. In the summer, the cattle barns are mainly used as storerooms. Sheep and horses are kept in pens outside the house districts when they are returned from the otur to the gacha, but they are not allowed in the barns. Livestock management during the winter, so-called 'wintering techniques', is somewhat different from how livestock are managed in the other seasons.

All livestock are kept at the house districts during the winter. Horses and sheep are particularly easy to look after, whilst the cattle need additional work. The most important work on early winter mornings is the removal of cattle manure from the barn. The manure is always kept exposed to the sun and where the wind blows as well as just outside the barn wall. This location choice improves the barn's resistance to wind and helps dry the manure so that it can be used as fuel during the coming spring. Moreover, milking has to be done twice a day regardless of the season. As we saw in the discussion about annual income, milk sales were the livestock farmers' principal source of income until recently. As such, many in the gacha kept non-native species that yielded large volumes of milk at times. However, the dairy factories kept down the milk prices, saying that the milk from the non-native species was low in nutrition, which had the effect that the milk cows' yield went down some years later. 
Furthermore, since they were not able to adapt to local weather and other environmental factors as well as native species, they were gradually culled, and native species have become more popular again in recent years. Machines were also used to milk the non-native species since their yield was high, but milking has become manual again with the return to native species.

In seasons other than winter, more or less all the gacha's horses are kept in one or two herds and allowed to run freely outside for several months. During this period, there is no need for any designated overseer as farmers only need to check where the herds are once every few days.

Work with the sheep is concentrated in the spring and summer. Every year, the peak of sheep giving birth is in the winter and spring. Since the rams are systematically let into the flocks for a month in the previous summer, most births take place around the New Year. The new-born lambs are taken indoors and kept there for two days so that they do not freeze to death. Pens are built inside the barns for especially weak and thin sheep and lambs, where they are kept for approximately a week. Lambs and kids that are rejected by their mother or whose mother has died are kept indoors for a month. During the day, the mother sheep and lambs are together, and the lambs can drink milk, whilst the sheep are given food inside the pens in the company of the lambs. They are separated at night to prevent the lambs from being trampled to death.

In the case of cattle, calves are always kept in separate pens and allowed to meet the cows only for milking. This separation of calves and cows is so that the cows can be milked. When a horse is born, the foals and mother horses are kept together, since horses are not milked for human use so their milk does not need to be regulated.

\section{CONCLUSION}

In this paper, I have discussed the economic circumstances of pastoralism in Gacha A. I summarize my findings below.

Firstly, looking at the number and structure of the livestock, the situation in Gacha A has some unique characteristics as compared to pastoralism in the Hulunbuir area as a whole. That is, whilst the majority of the Hulunbuir-area pastoralism is focused on livestock and especially sheep sales by medium- and large-sized pastoral businesses, the value of sheep as food is emphasized in Gacha A while the primary source of revenue tends to be the dairy economy in the form of milk sales. Even so, it is not simply structured as a dairy economy, but there are several sources of revenue characterized by diverse and rich economic activities, mainly on small-scale pastoralism. However, with the development of non-renewable resources such as coal, which is used to fuel the economic development of all of China, this economic structure is being scaled up and simplified, so that temporary economic gain might come with the risk of long-term economic weakness.

Next, the use of pastures is divided into grazing and hay-mowing, with the mowing grounds being opened up for grazing after the autumn harvest. This pasture use arises from the demands of semi-settled pastoralism. However, looking at the actual use of the pastures, we see that there is no clear line between pastures and common land. As the partitioning off of land incurred significant transaction costs, local social relations functioned to regulate it in an ad-hoc manner. 
Lastly, although livestock breeding very much relies on local knowledge and techniques as a kind of productive activity, we have also seen how the use of resources in the production processes are intimately tied to the aforementioned social relations.

Taking into consideration these insights, we wish to make the following conclusion. For the Solon Evenki people, livestock farming is more than just a productive activity; the logic of communities mediates it, and there is also an ideological aspect to it, in which their worldview is connected to the practice of livestock farming. Moreover, such productive activities are not isolated as something peculiar to them; they are also partially open to the market economy.

\section{References}

Hayami, Y., Development Economics, 1995, Tokyo: Sobunsha (Japan) (in Japanese).

Bo Jorgal, Luo Chun and Tan Xin, The Evenki People: A survey of the gacha of Ulan Bulag in the Evenki Autonomous Banner of Inner Mongolia, 2004, Kunming: Yunnan University Press (China) (in Chinese).

Editorial Committee of the Gazette of the Evenki Autonomous Banner, The Gazette of the Evenki Autonomous Banner, 1958-1991, 1996, Beijing: China City Press (China) (in Chinese).

National Ethnic Affairs Comission, Survey of the social history of the Evenki, 2009, Beijing: Ethnic Publishing (China) (in Chinese).

Du Hala, An overview of the Evenki Auotonomous Banner, 2008, Beijing: Ethnic Publishing (China) (in Chinese).

Sirenbat, ill. and Anna, Research on the ethnic culture of the Evenki, 2008, Tongliao: Inner Mongolia Cultural Publishing (China) (in Mongolia).

Kamimakise Saburo, The Society of the Solon People, 1940, Tokyo: Seikatsusha (Japan) (in Japanese).

Qiu Pu, Original social structure of the Evenki, 1962, Beijing: Zhonghua Book Company (China) (in Chinese)

Peter Knecht, Reindeer in Daxinganling and the Evenki barter bokshor, in Culture and society in Asian markets: An interdisciplinary look at distribution and exchange, 2005, Tokyo: Fukyosha (Japan), p.157-189 (in Japanese).

Yanagisawa Akira, Research on the formation and reorganization of the ethnic groups in the Heilongjiang region under the Qing Dynasty, in Report of Results for FY2004-2006 KAKENHI Grant-in-Aid Research Projects (Basic Research C), 2007 (in Japanese).

$\mathrm{Xi} \mathrm{Yu}$, Transfer and transformation: Functional research on the custom of deer-herding among the deer-using Evenki, 2004, Inner Mongolia Normal University Master's thesis (in Chinese).

Nasunmenghe and Yonekura Hitoshi, $A$ new role and organization for kinship groups after the introduction of the leasehold system in a Solon Evenki village (gacha), Research Reports on Agricultural Economy, 2017, 48, p.1-23 (in Japanese).

Toshimitsu Yuki, Otur Notes: On Mongolia's migrant pastoralists, Human Geography, 1983, 35(6) (in Japanese).

Editorial Committee of the Gazette of the Evenki Autonomous Banner(qi zhi), The Gazette of the Evenki Autonomous Banner, 2006-2016, 2018, Hulunbuir: Inner Mongolian Culture Press (China) (in Chinese). 